\title{
Temporal variation in male traits, nesting aggregations and mating success in the peacock blenny
}

\author{
R. F. Oliveira*, V. C. Almada, E. Forsgren† and E. J. Gonçalves \\ Unidade de Investigação em Eco-Etologia, Rua Jardim do Tabaco 44, 1100 Lisboa, \\ Portugal
}

(Received 21 May 1998, Accepted 28 October 1998)

\begin{abstract}
At the beginning of the breeding season male Salaria pavo that have eggs in their nests are larger, have more developed anal glands and less intense eye-spots and are located in breeding aggregations. These differences cease to occur from the peak of the breeding season (June-July) onwards. Two scenarios are presented that may explain these results: (1) smaller and younger males may begin to breed later devoting part of the warm season to growth; (2) females may cease to be selective as the nesting space begins to be saturated with eggs. These results raise one methodological and one conceptual question. The search for correlates of male reproductive success must cover different phases of the breeding season to capture the overall dynamics of the processes involved. The operational sex ratio for cavity-spawning fishes should take into account the availability of spawning sites rather than just counting the sexually mature members of each sex.

(C) 1999 The Fisheries Society of the British Isles
\end{abstract}

Key words: sexual selection; sexual dimorphism; mating success; intertidal fish.

\section{INTRODUCTION}

In recent years there has been an increasing interest in the study of sexually dimorphic traits. In particular, male secondary sex characters (SSC) have been viewed mainly as resulting from sexual selection, either because females have a preference for males with exaggerated traits (intersexual selection) or because the trait confers an advantage to their bearers in male-male competition (intrasexual selection) (Andersson, 1994). Alternatively, sexual dimorphism may be due to other mechanisms such as those related to pleiotropic gene effects or ecological differences between the sexes generating different selective regimes (Andersson, 1994). Finally, as stated by Barlow \& Siri (1997), the presence of an ornament in one of the sexes may simply be a signal for species or sex recognition.

Important factors that have been implied in mate choice in fish involve differences between the sexes in reproductive rate (Clutton-Brock \& Vincent, 1991; Clutton-Brock \& Parker, 1992), the operational sex ratio (Emlen \& Oring, 1977; Kvarnemo et al., 1995), and variation in mate quality (e.g. parental skills, Forsgren, 1997). Studying the processes of mate choice throughout a breeding season may be a fruitful strategy in this respect since many of the potential

*Author to whom correspondence should be addressed. Tel.: 3511 8811700; fax: 3511 8860954; email: ruiol@ispa.pt

$\uparrow$ Present address: Kristineberg Marine Research Station, Department of Marine Ecology, Göteborg University, S-45034 Fiskebäckskil, Sweden. 
factors affecting mate choice may themselves change as breeding progresses (e.g. temporal variation in nest availability, mate quality which is likely to be affected by current reproductive effort, etc.).

In blenniids, parental care is provided by the males that guard the eggs until hatching in crevices, holes, empty shells and other nesting cavities (Breder \& Rosen, 1966; Gibson, 1969; Wirtz, 1978; Thresher, 1984; Heymer, 1987; Almada \& Santos, 1995). Males tend to be larger than females, and exhibit a variety of SSC especially during the breeding season, such as enlarged supra-orbital tentacles [e.g. Aidablennius sphynx (Valenciennes, 1836), Parablennius spp.], crests on the head (e.g. Salaria spp.), enlarged dorsal fin (e.g. A. sphynx), glands on the anal spines (Salaria spp., Parablennius spp.), clublike glands on the tips of the soft rays of the dorsal, caudal and anal fins, and colour markings on the head and/or body (e.g. Lipophrys spp.) (Zander, 1975; Papaconstantinou, 1979; Heymer, 1987).

The peacock blenny Salaria pavo (Risso, 1810) exhibits a pronounced sexual dimorphism, with males attaining larger size than females (Papaconstantinou, 1979; author's unpubl. data), having head crests and anal glands especially developed in the breeding season, and a typical male nuptial coloration (Fishelson, 1963; Laumen et al., 1974; Patzner et al., 1986; Patzner \& Seiwald, 1987). This coloration consists of olive-green and brown vertical bars on the flanks, orange-yellow oblique stripes on the head and crest, and a pair of dark eye-spots with a blue iridescent ring on each side of the head (Fishelson, 1963; Patzner et al., 1986; Haymer, 1987; Abel, 1993). Although the species conforms to the basic blenniid breeding pattern (i.e. males guard eggs in a cavity where females come to spawn) they show a number of features that make the species particularly interesting.

(1) In some populations males form nest aggregations that are so dense that the territories are virtually absent (Almada et al., 1994).

(2) At least at the peak of the breeding season in some populations nest space becomes very scarce, becoming a limiting factor for female spawning (Moosleitner, 1980; Almada et al., 1994).

(3) This leads, at least in our study population, to sex-role reversal in courtship (Almada et al., 1995). Although males retain the capacity to court when they have no eggs in the nest, they usually assume a passive role in courtship while the females compete aggressively among themselves and actively court males displaying a female nuptial coloration (Almada et al., 1995).

(4) Male sexual polymorphism occurs with some small-sized males acting as sneakers and lacking the typical male SSC (Ruchon, 1995; Gonçalves et al., 1996).

In this paper we investigate the relationships between the degree of expression of male SSC, nest aggregations and male mating success over the season. Specifically, we addressed the following questions.

(1) If male SSC play a role in the acquisition of eggs (i.e. potential function in sexual selection) we would predict that males that have eggs in their nests differ in the expression of SSC from those that have no eggs.

(2) In addition, we would predict that as the breeding season progresses and the nests become saturated with eggs, the differences in the expression of 
SSC between nesting and non-nesting males would vanish due to a decrease in female selectivity.

(3) Another more descriptive question is whether the male characters change over the season.

\section{MATERIALS AND METHODS}

The study site is a large lagoon formed by a succession of sand barrier islands that run along the south coast of Portugal at Ria Formosa Nature Park $\left(36^{\circ} 59^{\prime} \mathrm{N}, 7^{\circ} 51^{\prime} \mathrm{W}\right)$. The lagoon is in permanent connection with the open sea. In intertidal mudflats there are several clam culture fields delimited by small reefs formed of several artificial materials, such as tiles, stones, sand sacks and bricks. The males of $S$. pavo use the brick cavities as nest sites, breeding from May to September (Almada et al., 1994). During low tide parental males as well as non-nesting males and females remain sheltered in or under the artificial material that forms the boundaries of the clam fields. For a detailed description of the area see Almada et al. (1994).

Data were collected during low tide in the breeding season of 1988, 1990, 1996 and 1997. Visits were made during the different months of the breeding season (May, June, July, August and September) and also in periods just prior to and after breeding. As the substrate conditions varied from year to year, two transects (total length $=50 \mathrm{~m}$ ) were established each year for regular inspections. The transects were made along ridges that delimited the clam fields. All the bricks, stones and other hard substrata found along the transects were inspected, and the fishes sheltering there were collected. For each fish sex was determined based on the inspection of the genital papillae, and the following measurements were taken: standard length, head height, body height, development of the anal gland in males, intensity of the blue coloration of the left and right eye-spot in males (see details below). In addition we noted the presence of eggs in the cavity and estimated the approximate percentage of the nest inner cavity surface covered by eggs. The presence of neighbours and nests (i.e. males or cavities with eggs in the same brick, respectively) was also recorded. After inspection both the fishes and the materials were carefully placed back in the same location and position. The handling of each fish and nest lasted only for a few minutes, and no anaesthetic was used. Apparently the disturbance was minimal and visits to the same sites in subsequent days showed that the parental males continued to guard the eggs and new spawnings took place. To study the relationship between male characteristics, their neighbourhood (i.e. number and type of neighbours) and mating success we used the following variables.

(1) Male characteristics.

(a) Body size was measured as standard length $\left(L_{\mathrm{S}}\right)$ to the nearest $\mathrm{mm}$. Since the correlation between standard length and body weight taken for 19 males was high ( $r=0.96, P<0 \cdot 001$, data from May 1988) standard length is a good measure of body mass and as it is easier to take in the field, it was preferred.

(b) Crest size (CS) was measured as the ratio between head height (including the crest) and body height taken at the insertion of the pectoral fins. Measures were taken to the nearest $\mathrm{mm}$.

(c) Anal gland development (AG) was measured according to the following scale: $0=$ absent; 1 =vestigial; 2 =developed; $3=$ well developed.

(d) Eye-spot intensity (ESI) is expressed as the average value between the left and right eye-spots measured according to a four-step scale of intensity $(0=$ pale, $3=$ very bright).

(2) Neighbourhood characteristics.

(a) Number of neighbours (i.e. number of nesting and non-nesting adult males in the same brick) was noted.

(b) Number of nests (i.e. number of cavities containing eggs in the same brick) was noted.

(3) Mating success was measured as the percentage of nest surface covered with eggs. Nest inspections were facilitated by using a flashlight. 
Only adult males were considered in the present study, neither sneaker males nor immatures were considered since the reproductive success of sneakers is not expected to be dependent on their SSC (which are not developed) and immature males are not sexually active. We considered a male as an adult if its standard length was $\geqslant 10.0 \mathrm{~cm}$ and/or if its crest size was $>1 \cdot 19$. These criteria were adopted since in previous studies it was shown that males mature at a smaller body and crest size (i.e. female-like males; Ruchon et al., 1995; Gonçalves et al., 1996).

Since it was not possible to take all measures in all sampling points the comparisons could not be based on multivariate methods (e.g. multiple regression models). Thus univariate tests were adopted, and the results presented below should be taken with caution since the features influencing female preferences, or in another way influencing mating success, may have more to do with the entire profile of traits of the male than to individual characteristics. In order to allow pooling of the data of the corresponding months in different years, the values of each variable were standardized (i.e. standard normal deviates; Sokal \& Rohlf, 1981) within years. Since the same male may stay in a nest for more than 1 month (Almada et al., 1994) there was a risk of non-independence between data points of consecutive months of the same year. To avoid this problem, we pooled data from equivalent months of different years and investigated the relationships between the above mentioned variables for each month of the breeding season. To study the seasonal variations of the variables studied across one breeding season we used the non-transformed data from 1996 for which we had monthly inspections from March to October. All the statistical procedures were run on the software package Statistica V. 5.0A (Statsoft Inc., U.S.A.). In the comparisons presented below parametric tests were used except when the data did not conform to the necessary assumptions, in which case non-parametric equivalents were adopted.

\section{RESULTS}

\section{CORRELATES OF MALE MATING SUCCESS}

To assess the importance of different male traits with male mating success we compared those traits between males with and without eggs, for each month of the breeding season (Table I). Of the 11 cases for which significant differences between the groups were found, most of them (eight) occurred at the beginning of the breeding season, and only one at the end.

In May egg-guarding males were significantly larger than males without eggs and also had more developed anal glands, and less intense eye-spots (Table I). Moreover, parental males had a higher number of nests in their neighbourhood (i.e. in the same brick) (Table I). Interestingly, there was a significant negative correlation between eye-spot intensity and the number of neighbours of each male $\left(n=41, r_{\mathrm{s}}=-0.55, P<0 \cdot 001\right)$, suggesting a social control of this trait.

Also in June parental males were larger than non-parental ones and they possessed larger anal glands (Table I). The association between the high number of egg-guarding neighbours and parental males was still significant (Table I) and, in addition, parental males had more neighbours in total (i.e. males, with or without eggs, in the same brick, Table I).

From July onwards the two groups of males no longer differed in the morphological traits measured except for the development of the anal gland in September (Table I). Regarding the patterns of aggregation, the differences found in the previous months were reversed in July (Table I), and no differences were found between the two groups in August and September.

We further investigated the possible role of male traits as determinants of mating success by analysing the relationship between their expression and the 
TABLE I. Differences ( $t$-test) between nesting and non-nesting males in morphological and nest location variables: standard length $\left(L_{\mathrm{S}}\right)$

\begin{tabular}{|c|c|c|c|c|c|c|}
\hline Variables & Male group & May & June & July & August & September \\
\hline \multirow{4}{*}{$L_{\mathrm{S}}$} & Nesting & $0 \cdot 47 \pm 0 \cdot 70$ & $0 \cdot 15 \pm 0 \cdot 98$ & $0 \cdot 07 \pm 1 \cdot 01$ & $-0.05 \pm 1 \cdot 07$ & $-0 \cdot 38 \pm 1 \cdot 01$ \\
\hline & Non-nesting & $-0 \cdot 56 \pm 0.86$ & $-0.39 \pm 0.93$ & $-0 \cdot 50 \pm 0 \cdot 71$ & $0 \cdot 16 \pm 1 \cdot 06$ & $0 \cdot 38 \pm 0 \cdot 81$ \\
\hline & $t$ value & $-5 \cdot 43(27,41)$ & $-2 \cdot 54(27,70)$ & $-1 \cdot 45(7,46)$ & $0 \cdot 55(9,27)$ & $1 \cdot 75(9,9)$ \\
\hline & $P$ & $<0.001$ & $<0.05$ & $\mathrm{NS}$ & NS & NS \\
\hline \multirow[t]{4}{*}{$\mathrm{CS}$} & Nesting & $0 \cdot 04 \pm 1 \cdot 00$ & $0 \cdot 03 \pm 1 \cdot 05$ & $0 \cdot 01 \pm 1 \cdot 00$ & $0 \cdot 03 \pm 1 \cdot 05$ & $0.06 \pm 0.88$ \\
\hline & Non-nesting & $-0 \cdot 01 \pm 1 \cdot 03$ & $-0 \cdot 09 \pm 0 \cdot 80$ & $-0.06 \pm 0.93$ & $-0.09 \pm 0.80$ & $-0 \cdot 06 \pm 1 \cdot 10$ \\
\hline & $t$ value & $-0 \cdot 20(26,41)$ & $-0 \cdot 54(27,70)$ & $-0 \cdot 17(7,46)$ & $-0 \cdot 31(9,27)$ & $-0 \cdot 26(9,9)$ \\
\hline & $P$ & NS & NS & NS & $\mathrm{NS}$ & $\mathrm{NS}$ \\
\hline \multirow[t]{4}{*}{$\mathrm{AG}$} & Nesting & $1 \cdot 09 \pm 1 \cdot 14$ & $0 \cdot 40 \pm 0 \cdot 43$ & $0 \cdot 89 \pm 1 \cdot 22$ & $0 \cdot 09 \pm 0 \cdot 77$ & $1.59 \pm 0.52$ \\
\hline & Non-nesting & $0 \cdot 30 \pm 1 \cdot 20$ & $-0 \cdot 92 \pm 1 \cdot 30$ & $0 \cdot 57 \pm 1 \cdot 50$ & $-0 \cdot 26 \pm 1 \cdot 47$ & $-0 \cdot 21 \pm 1 \cdot 15$ \\
\hline & $t$ value & $-2 \cdot 70(27,40)$ & $-0 \cdot 32 *(10,23)$ & $-0 \cdot 62(7,45)$ & $-0 \cdot 08 *(9,26)$ & $-3 \cdot 07(9,10)$ \\
\hline & $P$ & $<0 \cdot 01$ & $<0.001$ & NS & $\mathrm{NS}$ & $<0.01$ \\
\hline \multirow[t]{4}{*}{ ESI } & Nesting & $-0.34 \pm 0.92$ & $-0.06 \pm 1 \cdot 02$ & $-0.06 \pm 1.08$ & $0 \cdot 03 \pm 1 \cdot 04$ & $-0 \cdot 14 \pm 0 \cdot 84$ \\
\hline & Non-nesting & $0 \cdot 29 \pm 0 \cdot 97$ & $0.47 \pm 0.70$ & $0 \cdot 30 \pm 0 \cdot 31$ & $-0.08 \pm 0.99$ & $0 \cdot 66 \pm 1 \cdot 11$ \\
\hline & $t$ value & $2 \cdot 13(22,19)$ & $-0 \cdot 81 *(4,34)$ & $-0 \cdot 64 *(5,26)$ & $-0 \cdot 19(5,13)$ & $-0 \cdot 23^{*}(7,3)$ \\
\hline & $P$ & $<0.05$ & NS & NS & NS & NS \\
\hline \multirow{4}{*}{ Neighbours } & Nesting & $1 \cdot 44 \pm 1 \cdot 04$ & $3 \cdot 38 \pm 3 \cdot 05$ & $1 \cdot 26 \pm 0 \cdot 94$ & $2 \cdot 57 \pm 2 \cdot 64$ & $0 \cdot 40 \pm 0 \cdot 70$ \\
\hline & Non-nesting & $1 \cdot 18 \pm 1 \cdot 10$ & $1 \cdot 18 \pm 2 \cdot 01$ & $2 \cdot 83 \pm 1 \cdot 85$ & $2 \cdot 31 \pm 2 \cdot 57$ & $1 \cdot 00 \pm 0 \cdot 84$ \\
\hline & $t$ value & $-0 \cdot 79(22,23)$ & $-2 \cdot 86(17,96)$ & $-2 \cdot 92 *(18,27)$ & $-0 \cdot 34(16,56)$ & $1 \cdot 69(11,10)$ \\
\hline & $P$ & NS & $<0 \cdot 01$ & $<0 \cdot 01$ & NS & NS \\
\hline \multirow{4}{*}{ Nests } & Nesting & $0 \cdot 78 \pm 0.67$ & $3 \cdot 02 \pm 3 \cdot 06$ & $1 \cdot 11 \pm 1 \cdot 05$ & $1 \cdot 96 \pm 2 \cdot 14$ & $0 \cdot 20 \pm 0 \cdot 42$ \\
\hline & Non-nesting & $0 \cdot 22 \pm 0 \cdot 66$ & $1 \cdot 13 \pm 1 \cdot 96$ & $2 \cdot 61 \pm 2 \cdot 06$ & $1 \cdot 88 \pm 2 \cdot 41$ & $0 \cdot 18 \pm 0 \cdot 41$ \\
\hline & $t$ value & $-2 \cdot 12(9,23)$ & $-2 \cdot 39(16,96)$ & $-2 \cdot 32 *(18,27)$ & $-0 \cdot 14(16,56)$ & $-0 \cdot 10(11,10)$ \\
\hline & $P$ & $<0.05$ & $<0.05$ & $<0 \cdot 05$ & NS & NS \\
\hline
\end{tabular}

CS, Crest size (head height/body height); AG, anal gland development; ESI, eye-spot intensity; Neighbours, number of other males present in the brick of the focal male; Nests, number of nests present in the brick of the focal male. Mean values and S.D. for each group (nesting and non-nesting males) are given in within-year standard normal deviates except for the number of neighbours and for the number of neighbouring nests. Sample sizes for each group are presented between parentheses below each $t$ value $\left(n_{\text {non-nesting, }}, n_{\text {nesting }}\right)$. Non-significant differences are indicated by NS $(P>0 \cdot 10)$. An asterisk indicates cases for which non-parametric tests were used and the values refer to the Mann-Whitney test. 
percentage of nest surface occupied by eggs for each month of the breeding season. Males without eggs were excluded from this phase of the analysis. From the traits considered we only found significant correlations between the development of the anal gland and the percentage of nest surface covered by eggs in May $(n=40, r=0 \cdot 71, P<0.001)$ and September $\left(n=9, r_{\mathrm{s}}=0.98, P<0.001\right)$.

\section{SEASONAL VARIATION OF THE SECONDARY SEX CHARACTERS AND DEMOGRAPHIC PARAMETERS}

The size of adult males found in the transects decreased throughout the breeding season [Fig. 1(a)]. The head crest had intermediate values both at the beginning and at the end of the breeding season with a significant increase during intermediate months of the breeding season, ranging from a minimum in June to a maximum value in August [Fig. 1(b)]. The development of the anal gland appeared to decline slowly during the breeding season with a significant decrease at its end [Fig. 1(c)]. Concerning the intensity of the eye-spots there were no significant variations among the months of the breeding season (one-way analysis of variance, ANOVA: $\left.F_{4,107}=0 \cdot 76, P=0 \cdot 55\right)$.

Both the number of neighbouring males [Fig. 2(a)] and nests [Fig. 2(b)] (i.e. the number of males and the number of nests in the brick of the focal male, respectively) were low both at the beginning and at the end of the breeding season and a significantly higher number was found in the middle months of the breeding season. A similar pattern of temporal variation was found for the sex ratio, measured as the percentage of males present in the low tide transects, and for the number of nests found in the transects (Fig. 3).

The percentage of the nest area covered by eggs increased markedly after the beginning of the breeding season (from May to June), followed by a slow but significant decrease up to its end (from July to September) (Fig. 4).

\section{DISCUSSION}

The measure used for mating success has several limitations and has only an indicative value. In blenniids the eggs are spawned in a single layer of uniform density (Fishelson, 1963; Patzner, 1984; unpubl. observations) and the surface area of a cavity covered by eggs is roughly proportional to the total number of eggs (unpublished data for S. pavo and Lipophrys pholis (L.), Kraak, 1994 for A. sphynx). In addition, although some variation in size occurred among nests, the fact that they were located in man-made objects (i.e. bricks) limited the amount of nest size variation. The measure adopted was not intended to provide an accurate estimate of the total number of eggs but was rather an indicator of the spawning success of the males.

With this limitation in mind, the data suggest that larger males with moredeveloped anal glands and less-intense eye-spots were more successful in getting eggs into their nests. This could be the result of either female mate choice or male competition for breeding sites.

Several studies have demonstrated female preferences for larger males in species with male parental care (e.g. for blennioids: Thompson, 1986; Hastings, $1988 a, b$; Petersen, 1988; Côté \& Hunte, 1989; for a general review see Andersson, 1994). Females may benefit from this choice in a direct way if larger 

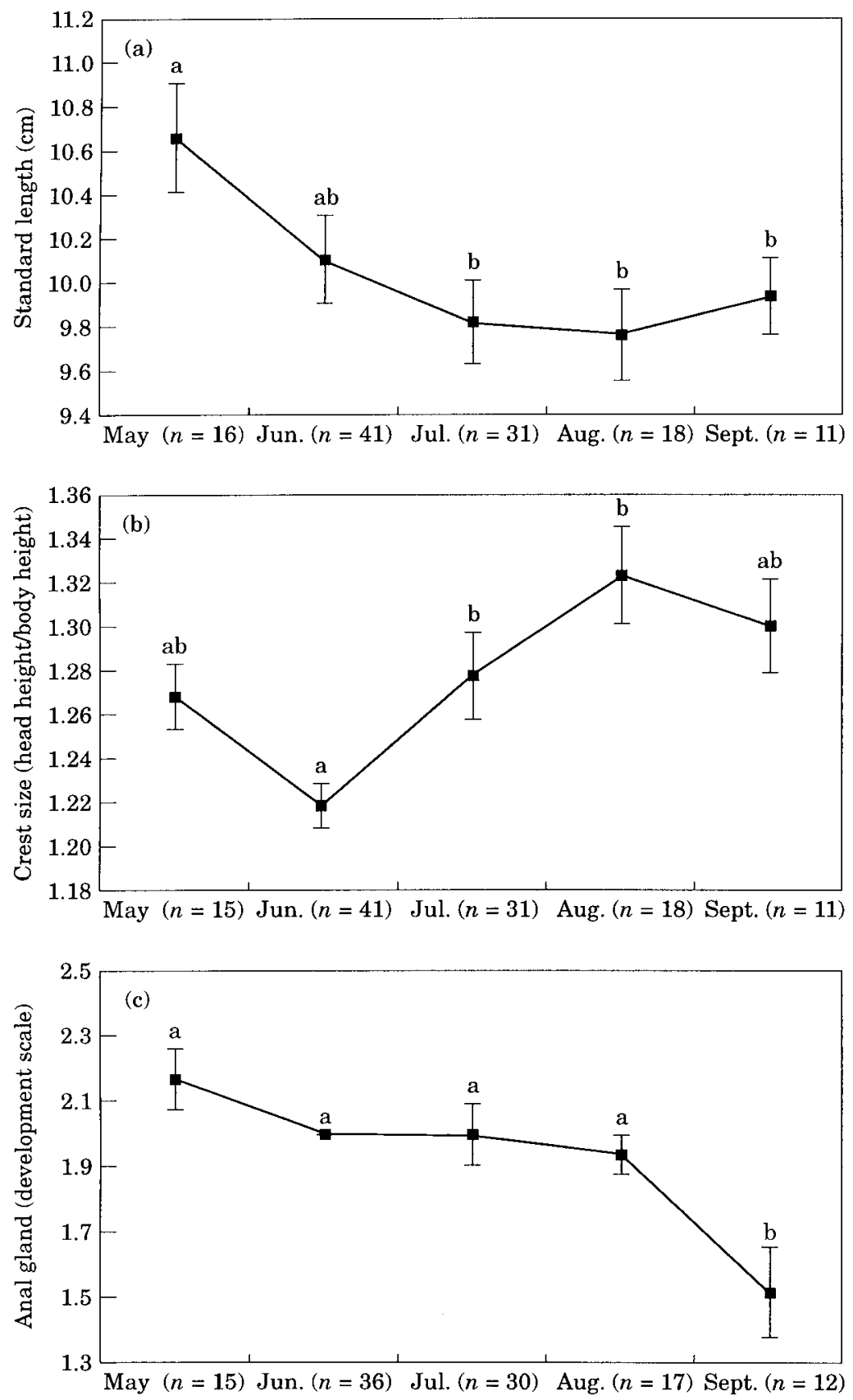

Breeding season

FIG. 1. Temporal variation (mean \pm S.E.) of the sexually dimorphic traits of the adult males present in the low-tide transects throughout the breeding season: (a) body size; (b) crest size; (c) anal gland. Different letters indicate significant differences in the means between groups (planned comparisons, $P<0 \cdot 05)$. 


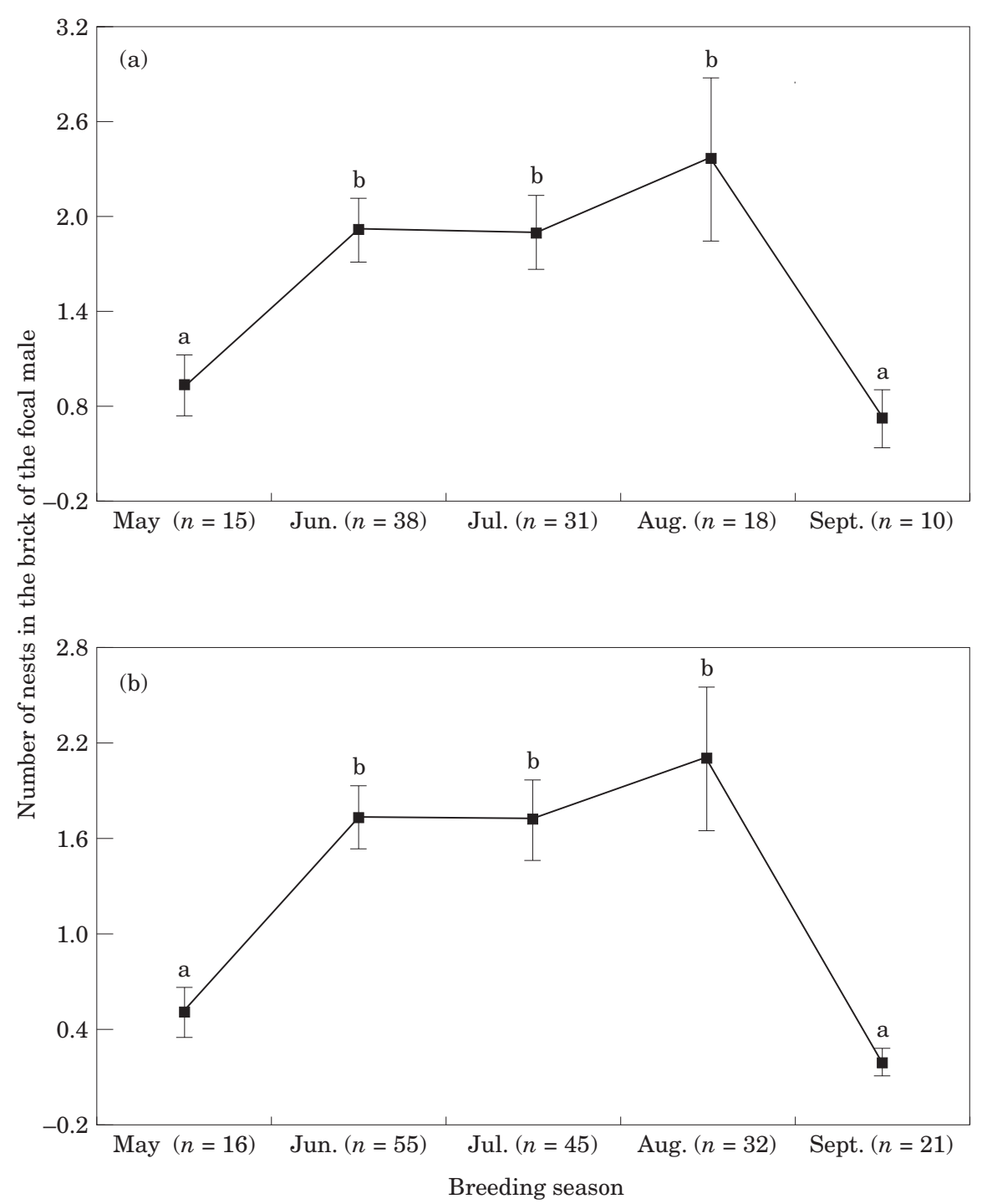

FIG. 2. Temporal variation (mean \pm S.E.) of the number of males (a) and of the number of nests (b) present in the brick of the focal male (neighbouring nests) throughout the breeding season. Different letters indicate significant differences in the means between groups (planned comparisons, $P<0 \cdot 05$ ).

males are more efficient in defending their nests against predators (Keenleyside et al., 1985), less susceptible to suffer take-overs from other males (Sheppey \& Ribbink, 1985) and more likely to possess reserves that allow them to keep guarding until the incubation period is completed (Perrone, 1978; Downhower \& Brown, 1980; Downhower et al., 1983; Colgan \& Salmon, 1986). Also, one cannot exclude indirect benefits, such as the potential heritability of body size leading to the production of sons that would be better competitors. Furthermore, size might indicate ability to survive (for a review on potential indirect benefits see Turner, 1993; Andersson, 1994). 


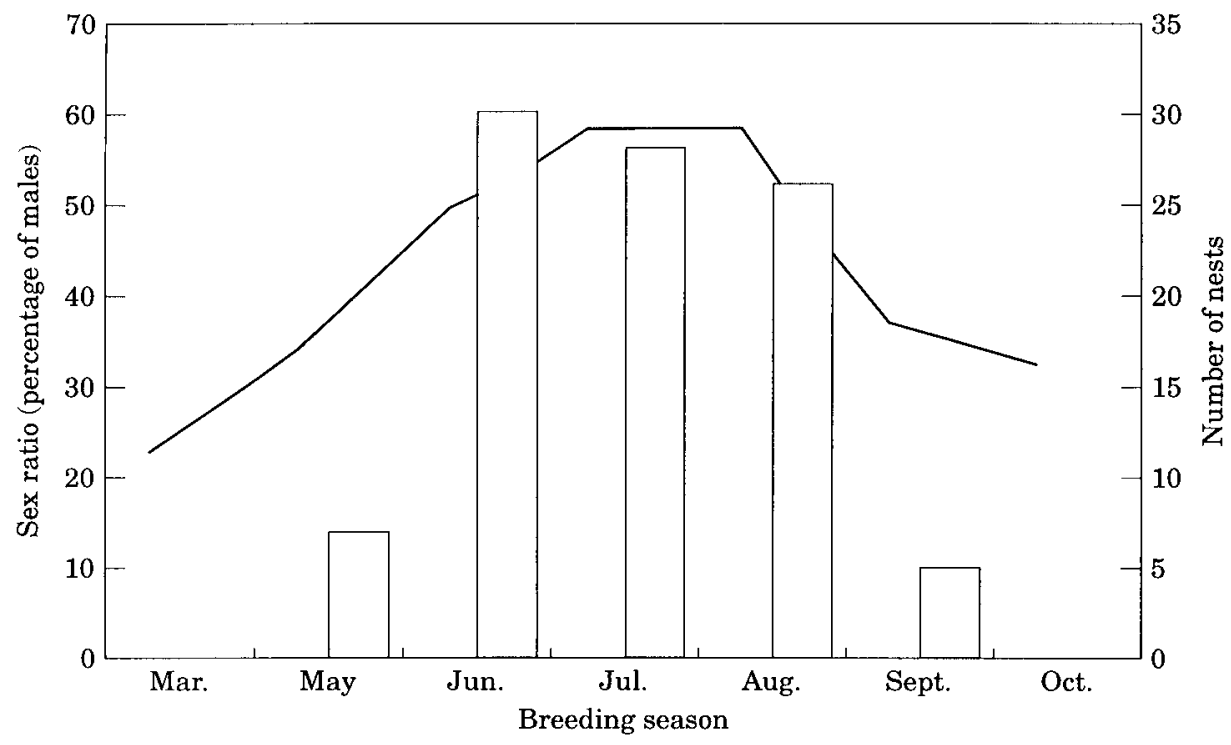

FIG. 3. Temporal variation of the sex ratio and of the number of nests (goodness-of-fit $\chi^{2}=30 \cdot 77$, d.f. $=4$, $P<0 \cdot 0001)$ present in the transects throughout the breeding season.

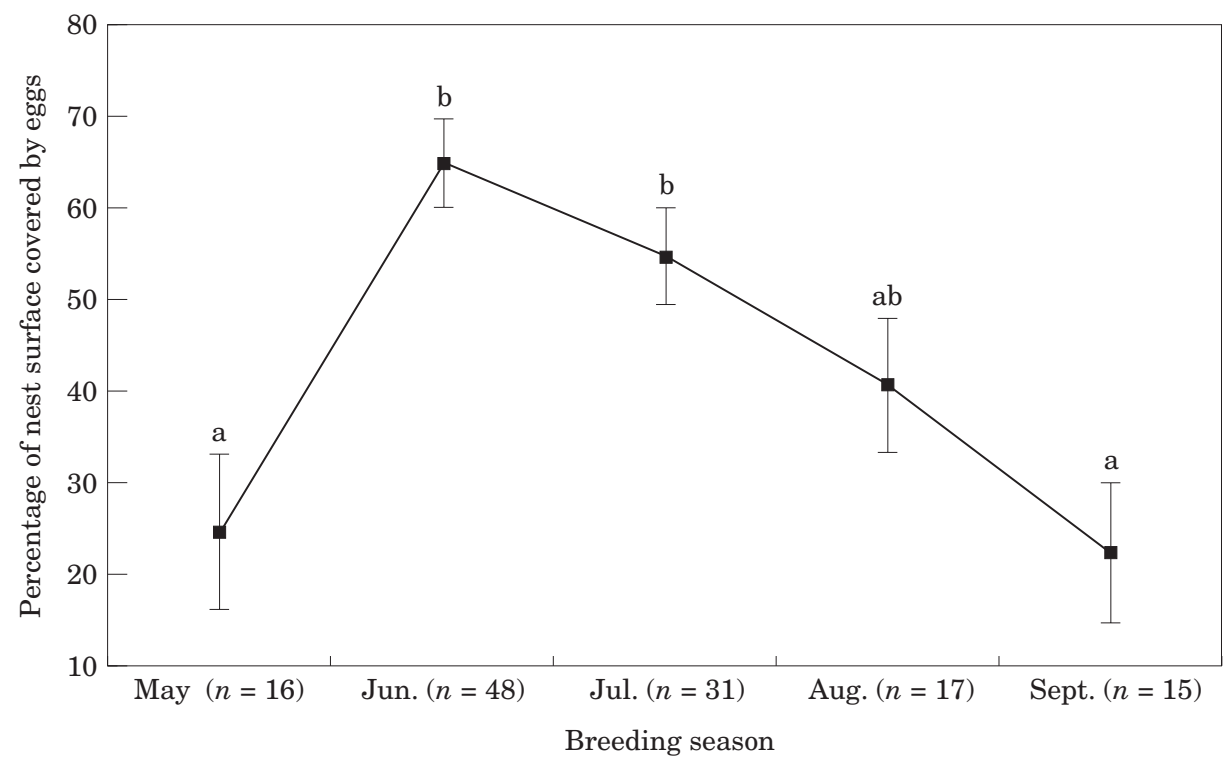

FIG. 4. Temporal variation (mean \pm S.E.) of the percentage of nest surface covered by eggs in the nests present in the low-tide transects throughout the breeding season. Different letters indicate significant differences in the means between groups (planned comparisons, $P<0 \cdot 05$ ).

The development of the anal gland is known to be correlated with gonadal maturation in blenniids (Patzner \& Seiwald, 1987; Santos, 1995), and in S. pavo it is known to secrete a male pheromone that seems to attract females and evoke 
their nuptial coloration (Laumen et al., 1974; Zeeck \& Ide, 1996). Thus, males with a more developed gland might attract more females to their nests.

The eye-spots seem to play a role as sexual signals as their blue coloration becomes more intense during courtship episodes (Fishelson, 1963). The fact that we found a negative correlation between eye-spot intensity and the number of neighbours suggests that this trait might also be under social control.

The crest probably plays an important role as a signal both to other males and females. Indeed, during the field observations the presence of the males with their heads and crests protruding at the nest entrances was conspicuous, at least to human observers. In addition, sneaker males that engage in female-like mimicry lack crests. However, the development of the crest did not show significant differences between males with and without eggs. We suggest that the lack of differences in crest development between nesting and non-nesting males may be an artifact from the way the adult males were defined operationally. Indeed, we dealt only with males with a crest size $\geqslant 1 \cdot 2$ (head height/body height), and so, automatically, did not include the left tail of the crest size distribution. This was necessary because we wanted to exclude from the analysis both large but immature males and female-like sneaker males. The importance of the crest for male mating success needs further investigation.

In the first months of the breeding season, males that have eggs have a higher number of neighbours (i.e. other males in the same brick) than non-nesting males. One explanation for these male aggregations could rely on a constraint imposed by a special pattern of distribution of potential nest site cavities. Salaria pavo prefers nest site cavities with a narrow entrance to a close chamber (Kotrschal, 1988; Almada et al., 1994). In the study area this type of cavity occurs in bricks or groups of bricks that have one of the ends obstructed and the other restricted (e.g. by clam shells or remains of cement). These preferred cavities tend to occur in patches instead of being randomly distributed (pers. obs.). In addition nesting males may be attractive to other males that would settle later in their vicinity (i.e. hotshot hypothesis; Arak, 1982; Beehler \& Foster, 1988).

A salient feature that emerges from the present study is the marked temporal variation in the role of different male traits as indicators of their ability to get eggs in their nests. While at the beginning of the breeding season several traits, including body size, anal gland development and eye-spot intensity distinguish the males that are guarding from those without eggs, these differences are almost absent when the season reaches its peak.

This could result from a decrease in female selectivity as the breeding season progresses. Nest sites are scarce in this population (Almada et al., 1994) and as the breeding season progresses, nests become saturated with eggs. At the peak of the breeding season males seldom court females, while females take the active role in courtship and compete aggressively among themselves for access to nests (Almada et al., 1995). It is common to observe a female courting a succession of males that chase her away until finally being accepted in a nest (pers. obs.). Although, the number of males in the nesting area increases in the middle of the breeding season the number of adequate nesting sites does not increase and so it is likely that the newly arrived males adopt cavities of progressively lower quality, while the females are likely to accept these inferior nests due to the lack of better options. 
Another line of evidence in favour of this interpretation is the finding that despite an increase in the number of nests towards the middle of the breeding season the percentage cover of eggs per nest also peaks at that time reaching average values of $50-60 \%$. These values probably represent the egg capacity of the nests since in blennids the first centimetres of the nest cavity near the entrance are seldom used for spawning (unpubl. data on L. pholis and S. pavo). Moreover, the capacity of the nests to receive eggs is likely to decrease as more clutches are spawned. This would mean that the limiting factor for females would not be the number of males but the amount of available spawning space.

In practice this scenario suggests that the operational sex ratio becomes biased towards females at the peak of the breeding season, promoting female competition and an opportunity for male mate choice in S. pavo. It has been shown that in the sand goby Pomatoschistus minutus (Pallas) experimental manipulation of the sex-ratio may affect strongly patterns of interactions among members of each sex, leading to a change from predominantly male to predominantly female competition, as the sex-ratio changes from a male biased to a female biased condition (Kvarnemo et al., 1995).

When we consider the variation in male traits during the breeding season the first feature that emerges is the gradual decrease of the average size of the males that settle in the nesting area. We suggest that the largest males are the first to establish nests and as they begin to guard eggs they reduce their excursions out of the nests allowing smaller males to settle in the remaining cavities. The interpretation is supported by two findings.

(1) It has been shown that the parental males of this population have virtually no territory except for the nest hole and reduce their movements out of the nest to a minumum (Gonçalves \& Almada, 1998).

(2) Prior to the onset of the breeding season males compete aggressively for nest sites with some individuals chasing others for several metres (pers. obs.).

The process hypthesized above would explain easily the increase in both the number of neighbouring males and neighbouring nests observed to the middle of the breeding season. This would correspond to a period when a number of small males have been able to settle while the large males were still present. The decrease in the number of neighbours and neighbouring nests towards the end of the breeding season would merely reflect the cessation of breeding. The patterns of variation of both sex ratio and the number of nests present in the transect are also consistent with this explanation.

The present study emphasizes two general issues:

(1) The search for correlates of male reproductive success must cover different phases of the breeding season to capture the overall dynamics of the processes involved.

(2) The operational sex ratio for cavity-spawning fishes should take into account the availability of spawning sites rather than just counting the sexually mature members of each sex.

The authors thank the staff of parque Natural da Ria Formosa for logistic support, especially N. Lecoq and L. Fonseca; and the following people for valuable help during the field work: A. J. dos Santos, R. Matos, M. Grober, K. McIntyre, F. Almada, 
D. Gonçalves, E. Rodrigues, L. Kvarnemo, S. Merilaita, K. Forsgren, A.-L. Forsgren and K. Gehlen. This study is part of a project funded by Fundação para a Ciência e a Tecnologia (PBIC/C/MAR/2228/95). E.F. was supported by a post-doctoral grant from the Commission of the European Communities DGXII (Program TMR, ERBFMBICT950068) and E.J.G. by a Ph.D. grant from JNICT (BD/872/90-IG).

\section{References}

Abel, E. F. (1993). Coloration phenomena of Mediterranean blennies (Pisces, Blenniidae). Marine Ecology (PSZNI) 14, 291-312.

Almada, V. C. \& Santos, R. S. (1995). Parental care in the rocky intertidal: a case study of adaptation and exaptation in Mediterranean and Atlantic blennies. Reviews in Fish Biology and Fisheries 5, 23-37.

Almada, V. C., Gonçalves, E. J., Santos, A. J. \& Baptista, C. (1994). Breeding ecology and nest aggregations in a population of Salaria pavo (Pisces: Blenniidae) in an area where nest sites are very scarce. Journal of Fish Biology 45, 819-830.

Almada, V. C., Gonçalves, E. J., Oliveira, R. F. \& Santos, A. J. (1995). Courting females: ecological constraints affect sex roles in a natural population of the blenniid fish Salaria pavo. Animal Behaviour 49, 1125-1127.

Andersson, M. (1994). Sexual Selection. Princeton, NJ: Princeton University Press.

Arak, A. (1982). Sneaky breeders. In Producers and Scroungers: Strategies of Exploitation and Parasitism (Barnard, C. J., ed.), pp. 154-194. London: Croom Helm.

Barlow, G. W. \& Siri, P. (1997). Does sexual selection account for the conspicuous head dimorphism in the Midas cichlid? Animal Behaviour 53, 573-584.

Beehler, B. M. \& Foster, M. S. (1988). Hotshots, hotspots and female preferences in the organization of lek mating systems. American Naturalist 131, 203-219.

Breder, C. M., Jr \& Rosen, D. E. (1966). Modes of Reproduction in Fishes. Jersey City, NJ: TFH Publications.

Clutton-Brock, T. H. \& Parker, G. A. (1992). Potential reproductive rates and the operation of sexual selection. Quarterly Reviews in Biology 67, 437-456.

Clutton-Brock, T. H. \& Vincent, A. C. J. (1991). Sexual selection and the potential reproductive rates of males and females. Nature 351, 58-60.

Colgan, P. W. \& Salmon, A. B. (1986). Breeding experience and parental behaviour in convict cichlids (Cichlasoma nigrofasciatum). Behavioural Processes 13, $101-118$.

Côté, I. M. \& Hunte, W. (1989). Male and female mate choice in the redlip blenny: why bigger is better. Animal Behaviour 38, 78-88.

Downhower, J. F. \& Brown, L. (1980). Mate preferences of female mottled sculpins, Cottus bairdi. Animal Behaviour 28, 728-734.

Downhower, J. F., Brown, L., Pederson, R. \& Staples, G. (1983). Sexual selection and sexual dimorphism in mottled sculpins. Evolution 37, 96-103.

Emlen, S. T. \& Oring, L. W. (1977). Ecology, sexual selection, and the evolution of mating systems. Science 197, 215-223.

Fishelson, L. (1963). Observations on littoral fishes of Israel I. Behaviour of Blennius pavo Risso (Teleostei, Blenniidae). Israel Journal of Zoology 12, 67-80.

Forsgren, E. (1997). Female sand gobies prefer good fathers over dominant males. Proceedings of the Royal Society B264, 1283-1286.

Gibson, R. N. (1969). The biology and behaviour of littoral fish. Oceanography and Marine Biology Annual Review 7, 367-410.

Gonçalves, E. J. \& Almada, V. C. (1998). A comparative study of territoriality in intertidal and subtidal blennioids (Teleostei, Blennoidei). Environmental Biology of Fishes 51, 257-264.

Gonçalves, E. J., Almada, V. C., Oliveira, R. F. \& Santos, A. J. (1996). Female mimicry as a mating tactic in males of the blenniid fish Salaria pavo. Journal of the Marine Biological Association of the United Kingdom 76, 529-538. 
Hastings, P. A. (1998a). Female choice and male reproductive success in the angel blenny, Coralliozetus angelica (teleostei: Chaenopsidae). Animal Behaviour 36, $115-124$.

Hastings, P. A. (1988b). Correlates of male reproductive success in the browncheek blenny, Acanthemblemaria crockeri (Blennioidea: Chaenopsidae). Behavioral Ecology and Sociobiology 22, 95-102.

Heymer, A. (1987). Comportement agonistique, stratégies reproductives et investissement parental chez Blennius basiliscus (Teleostei, Blenniidae). Revue Française d'Aquariologie 12, 39-52.

Keenleyside, M. H. A., Rangeley, R. W. \& Kuppers, B. U. (1985). Female mate choice and parental defense behaviour in the cichlid fish Cichlasoma nigrofasciatum. Canadian Journal of Zoology 63, 2489-2493.

Kotrschal, K. (1988). Blennies and endolithic bivalves: differential utilization of shelter in Adriatic Blenniidae (Pisces: Teleostei). Marine Ecology (PSZNI) 9, 253-269.

Kraak, S. B. M. (1994). Female mate choice in Aidablennius sphynx, a fish with paternal care for eggs in a nest. Ph.D. thesis, University of Groningen.

Kvarnemo, C., Forsgren, E. \& Magnhagen, C. (1995). Effects of sex-ratio on intra- and inter-sexual behaviour in sand gobies. Animal Behaviour 50, 1455-1461.

Laumen, J., Pern, U. \& Blüm, V. (1974). Investigations on the function and hormonal regulations of the anal appendices in Blennius pavo. Journal of Experimental Zoology 190, 47-56.

Moosleitner, H. (1980). Zentrale Laichstelle ermöglicht Blennius pavo, Risso 1810 (Blenniidae, Perciformes, teleostei) die Besiedlung von Sandgrund. Zoologischer Anzeiger 204, 82-88.

Papaconstantinou, C. A. (1979). Secondary sex characters of Blennioid fishes (Pisces: Blenniidae). Thalassographica 1, 57-75.

Patzner, R. A. (1984). The reproduction of Blennius pavo. II. Surface structures of the ripe egg. Zoologischer Anzeiger 213, 44-50.

Patzner, R. A. \& Seiwald, M. (1987). The reproduction of Blennius pavo. II. Secondary sexual organs and accessory glands of the testis during the reproductive cycle. In Proceedings of the $V$ Congress of European Ichthyologists, Stockholm 1985 (Kullander, S. \& Fernholm, B., eds), pp. 293-298. Stockholm: Swedish Museum of Natural History.

Patzner, R. A., Seiwald, M., Adlgasser, M. \& Kaurin, G. (1986). The reproduction of Blennius pavo. V. Reproductive behaviour in the natural environment. Zoologischer Anzeiger 216, 338-350.

Perrone, M. J. (1978). Mate size and breeding success in a monogamous cichlid fish. Environmental Biology of Fishes 3, 193-201.

Petersen, G. W. (1988). Male mating success, sexual size dimorphism, and site fidelity in two species of Malacoctenus (Labrisomidae). Environmental Biology of Fishes 21, $173-183$.

Ruchon, F., Laugier, T. \& Quignard, J. P. (1995). Alternative male reproductive strategies in the peacock blenny. Journal of Fish Biology 47, 826-840.

Santos, R. S. (1995). Anatomy and histology of secondary sexual characters, gonads and liver of the rock-pool blenny, Parablennius sanguinolentus parvicornis (Pisces: Blenniidae) of the Azores. Arquipélago, Life and Marine Sciences 13A, 21-38.

Sheppey, K. \& Ribbink, A. J. (1985). Mating interruption, an alternative to sexual selection in cichlid fish. South African Journal of Science 81, 702.

Sokal, R. R. \& Rohlf, F. J. (1995). Biometry, 3rd edn. New York: Freeman.

Thompson, S. (1986). Male spawning success and female choice in the mottled triplefin, Forsterygion varium (Pisces: Tripterygiidae). Animal Behaviour 34, 580-589.

Thresher, R. E. (1984). Reproduction in Reef Fishes. Neptune City, NJ: T.F.H. Publications.

Turner, G. F. (1993). Teleost mating behaviour. In The Behaviour of Teleost Fishes (Pitcher, T. J., ed.), pp. 307-331. London: Chapman \& Hall.

Wirtz, P. (1978). The behaviour of the Mediterranean Tripterygion species (Pisces, Blennioidei). Zeitschrift für Tierpsychologie 48, 142-174. 
Zander, C. D. (1975). Secondary sex characteristics of Blennoid fishes (Perciformes). Pubblicazioni della Stazioni Zoologica di Napoli 39, 717-727.

Zeeck, E. \& Ide, V. (1996). The role of sex pheromones in the reproductive behavior of Blennius pavo (Risso). In Fish Pheromones: Origins and Modes of Action (Canário, A. V. M. \& Power, D. M., eds), pp. 33-38. Faro: University of Algarve. 